\title{
LUNAR IGNEOUS ACTIVITY AND DIFFERENTIATION
}

\author{
G. FIELDER \\ University of Lancaster
}

\section{Observational Evidence of Volcanic Flows}

One of the most significant advances in our understanding of the Moon has been the discovery, through the Surveyor, Orbiter and Apollo programmes, of widespread lunar igneous activity and differentiation.

Volcanic flows (Figure 1) in, and in the neighbourhood of, Tycho are up to $20 \mathrm{~km}$ long and up to $12 \mathrm{~km}$ wide. At least 5 flows, mapped by Strom and Fielder (1970) originated in, and breached, craters up to $100 \mathrm{~km}$ from the rim of Tycho. One flow (Figure 2) is essentially the same age as the ropy floor material of Tycho, since it is traversed by cracks that are indicative of marginal stretching of the floor unit. Other flows are found in what are probably lava lakes (Figure 3), and two flows derive from such lakes.

The viscosity appears to have differed from one flow to another; the more viscous looking flows have the higher albedoes and, stratigraphically, are the younger ones with a lower number density of probable impact craters.

Turning to a second region, the flows in and around Aristarchus are up to $9 \mathrm{~km}$ long and are $400 \mathrm{~m}$ to $4 \mathrm{~km}$ wide. At least 14 of these flows originated in craters and one lake overflowed to produce an instructive flow (Figure 4) of large (length)/(width) ratio, in a direction tangential to the rim of Aristarchus.

All the flows mentioned appear to have run downslope. Most have flowed away from Tycho and Aristarchus, but several have flowed towards these craters. The Aristarchus flows are thinner, smoother, more lobate and less bright than the Tycho flows. Probably the lavas of Tycho were more highly differentiated than those of Aristarchus, which is in a mare site.

Assuming, with Vedder (1966), that 1 crater more than $50 \mathrm{~m}$ in diameter is generated by a primary impact per $1000 \mathrm{~km}^{2}$ of lunar surface every $1.8 \times 10^{5} \mathrm{yr}$, counts of probable impact craters may be used to date the viscous flows at a few times $10^{8} \mathrm{yr}$. This, together with their sharpness, indicates that they are very much younger than the mare rocks at the Apollo 11 and 12 sites ( 3.7 and $3.4 \times 10^{9} \mathrm{yr}$, respectively).

\section{Flow patterns in Maria}

Much more voluminous flows occur in the maria. Many with colour differences and fronts, in Mare Imbrium have been mapped by Kuiper, Strom and Whitaker, and reported by Fielder and Fielder (1968). The most notable flow (Figure 5) is $130 \mathrm{~km}$ long, 20 to $50 \mathrm{~km}$ wide and about $30 \mathrm{~m}$ thick, judging by the shadows cast by its fronts. From its dimensions, and the fact that parts of the front follow pre-existing, linear 


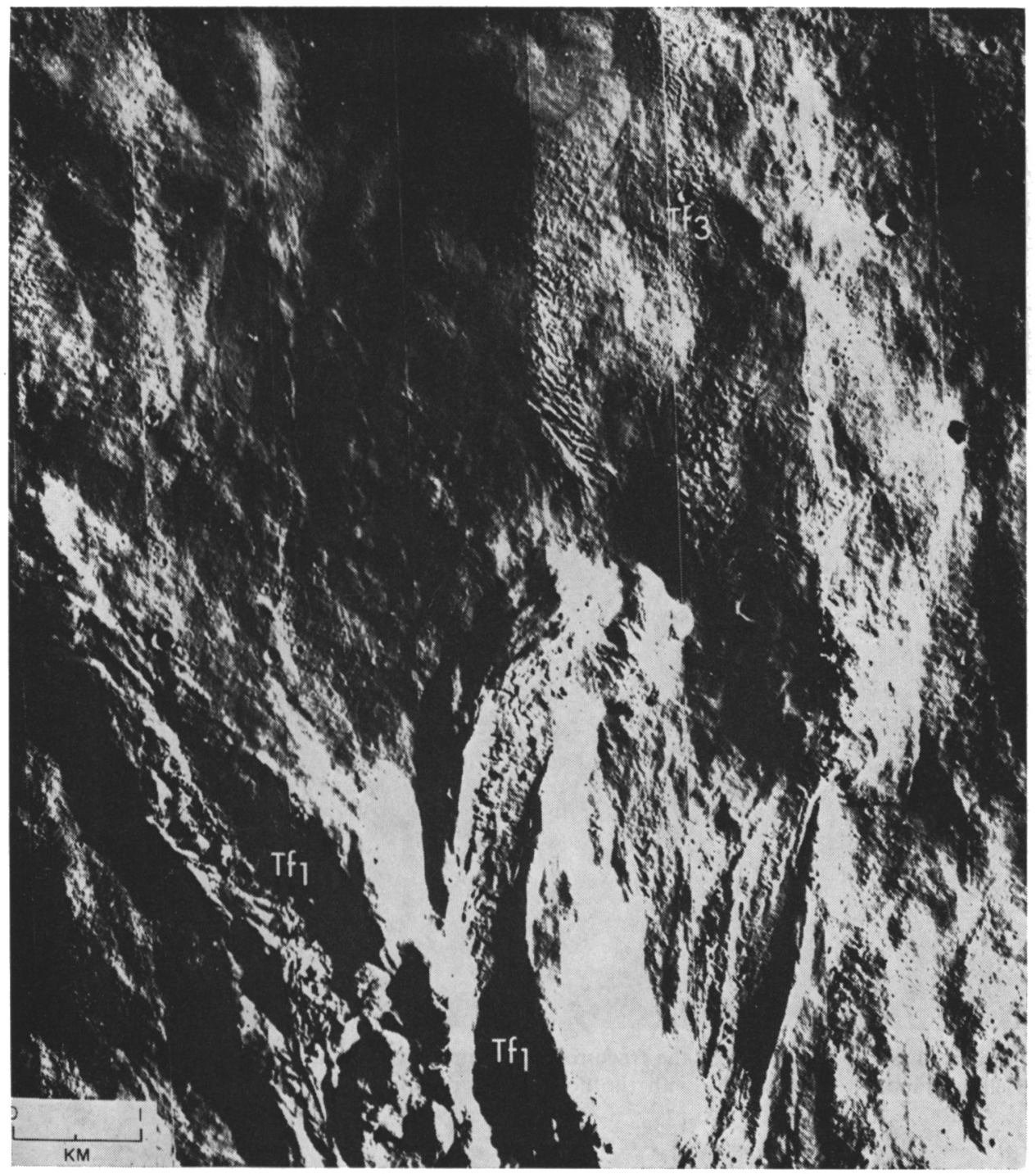

Fig. 1. Flows in the highlands in the neighbourhood of Tycho are labeled $T f_{1}$ and $T f_{3}$. 


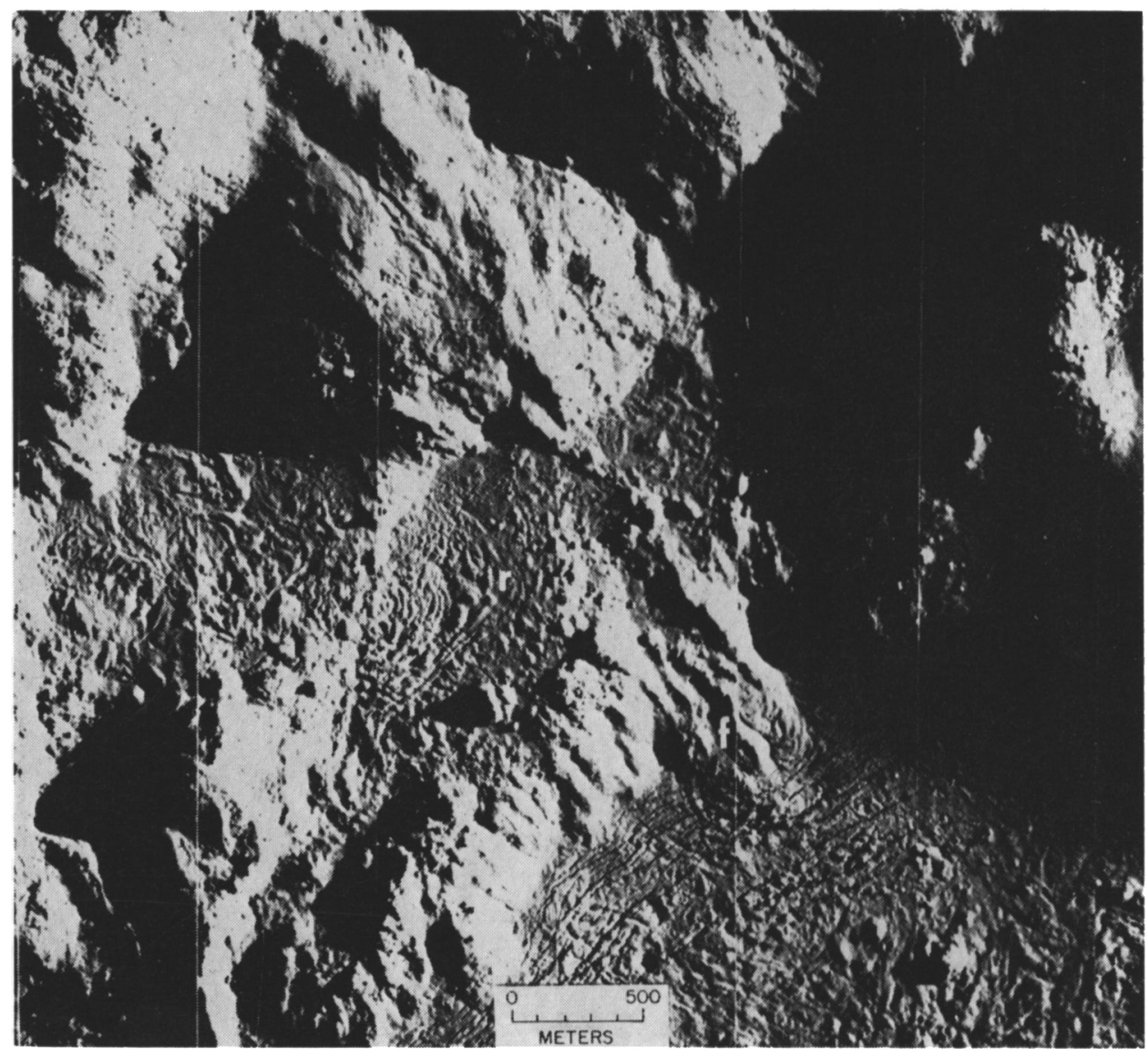

Fig. 2. The flow $f$ has crossed the fractured peripheral parts of the floor of Tycho and the flow itself is fractured in sympathy with the floor. Flow ridging is seen at $r$ in the wall of Tycho. 


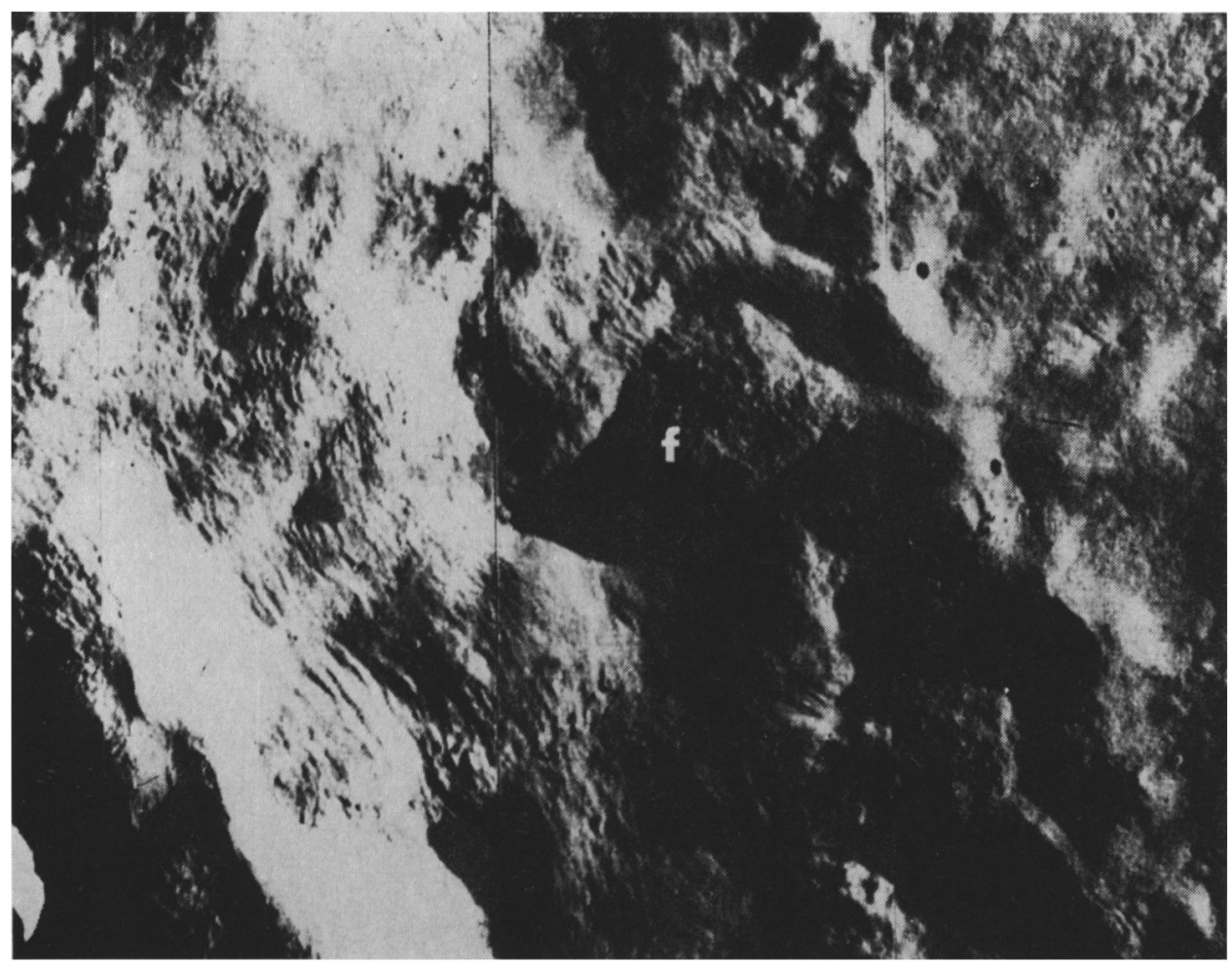

Fig. 3. A probable lava lake, $f$, in the rim unit of Tycho. The lake shows flow fronts. 


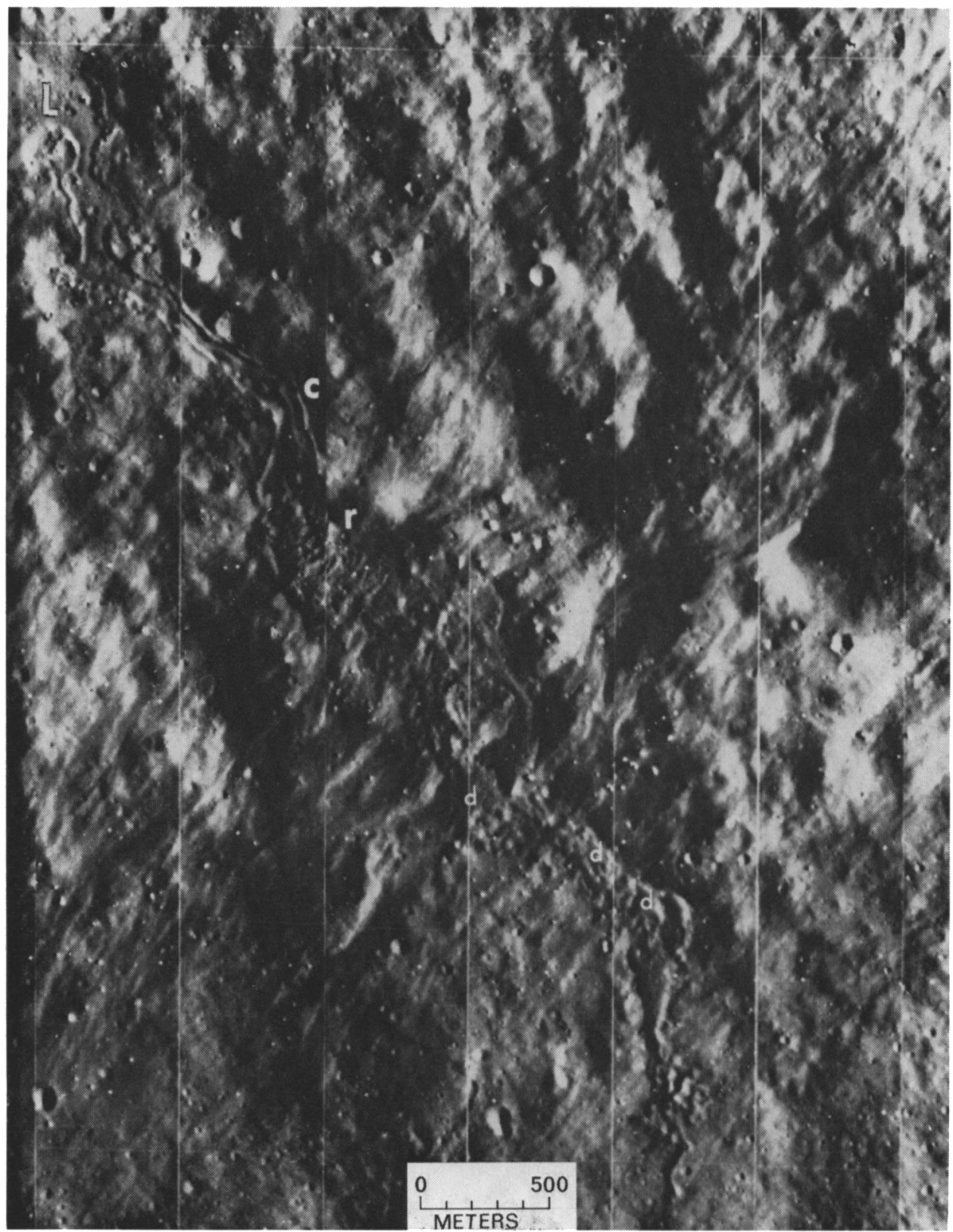

Fig. 4. A long, narrow flow that cuts across the subradial striae associated with Aristarchus derives from a probable lava lake $L$ (upper lefthand corner) and the flow may be followed through $c$, where there are levées; $r$, where there is flow ridging; and $d$, where there are numerous probable collapse depressions. 
undulations, it is concluded that the flow material must have been very much less viscous than the most viscous of the highland flows. Murase and McBirney (1970) measured synthetic silicates having the composition of a lunar rock returned from Mare Tranquillitatis and found the liquidus temperature to be in excess of $1300^{\circ} \mathrm{C}$ and the viscosity exceptionally low for lavas (it was similar to that of heavy motor oil at room temperature). When liquid lavas are upwelled in vacuo the contained gas generates a cover of rock froth. The rock froth is a good thermal insulator and floats on the liquid, allowing the flow to cover large distances before congealing.

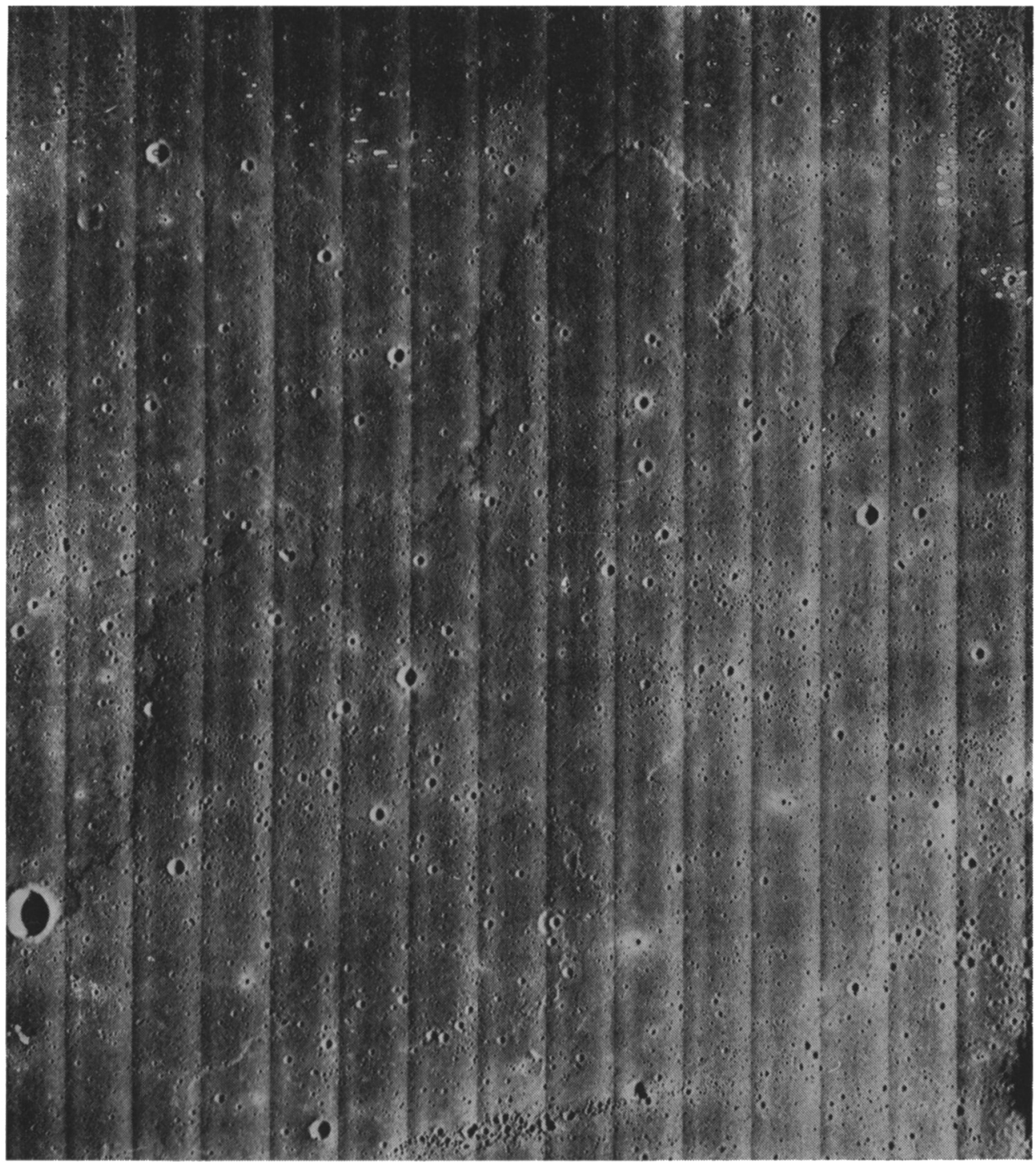

Fig. 5. A flow in Mare Imbrium measuring $130 \mathrm{~km}$ long times 20 to $50 \mathrm{~km}$ in width. 


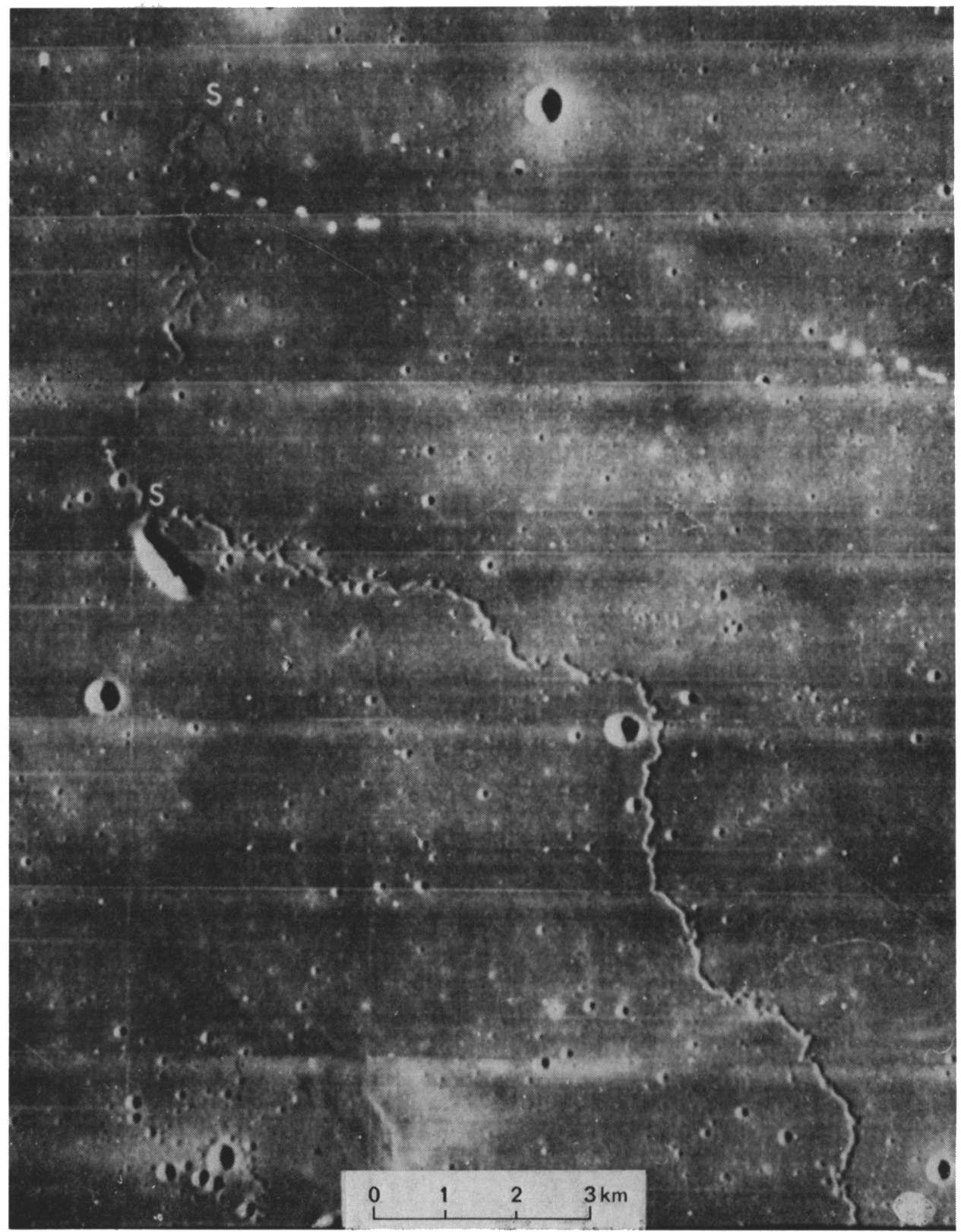

Fig. 6. A lunar sinuous rille. 
The Imbrium flow contains channels up to $8 \mathrm{~km}$ long and $180 \mathrm{~m}$ wide. They run in the direction of the flow and one of them has a possible distributory. The channels are similar to collapsed lava tubes.

The volume of the flow is about $100 \mathrm{~km}^{3}$. All the mapped flows have a volume of the order of $1000 \mathrm{~km}^{3}$ and occupy about $10 \%$ of Mare Imbrium. The implication is that there may be $\approx 10^{4} \mathrm{~km}^{3}$ of lavas in the whole of Mare Imbrium. If these lavas were as dense as those returned from Mare Tranquillitatis (but were much thicker) then one might have an explanation of the Mare Imbrium mascon - a mass concentration or positive gravity anomaly discovered by Muller and Sjogren (1968).

Mare ridges are the sources of the longest flows in Mare Imbrium. The deduction that vast volumes of rock have been melted at depth in the Moon and then extruded finds support in the high content of radioactive elements in rocks returned from the Apollo missions.

\section{Sinuous Rilles}

Another class of feature in the lunar maria that has been studied in detail in the last three years is the sinuous rille. Before it was generally recognized that lunar lavas could be very hot and of extremely low viscosity it had been suggested by some that

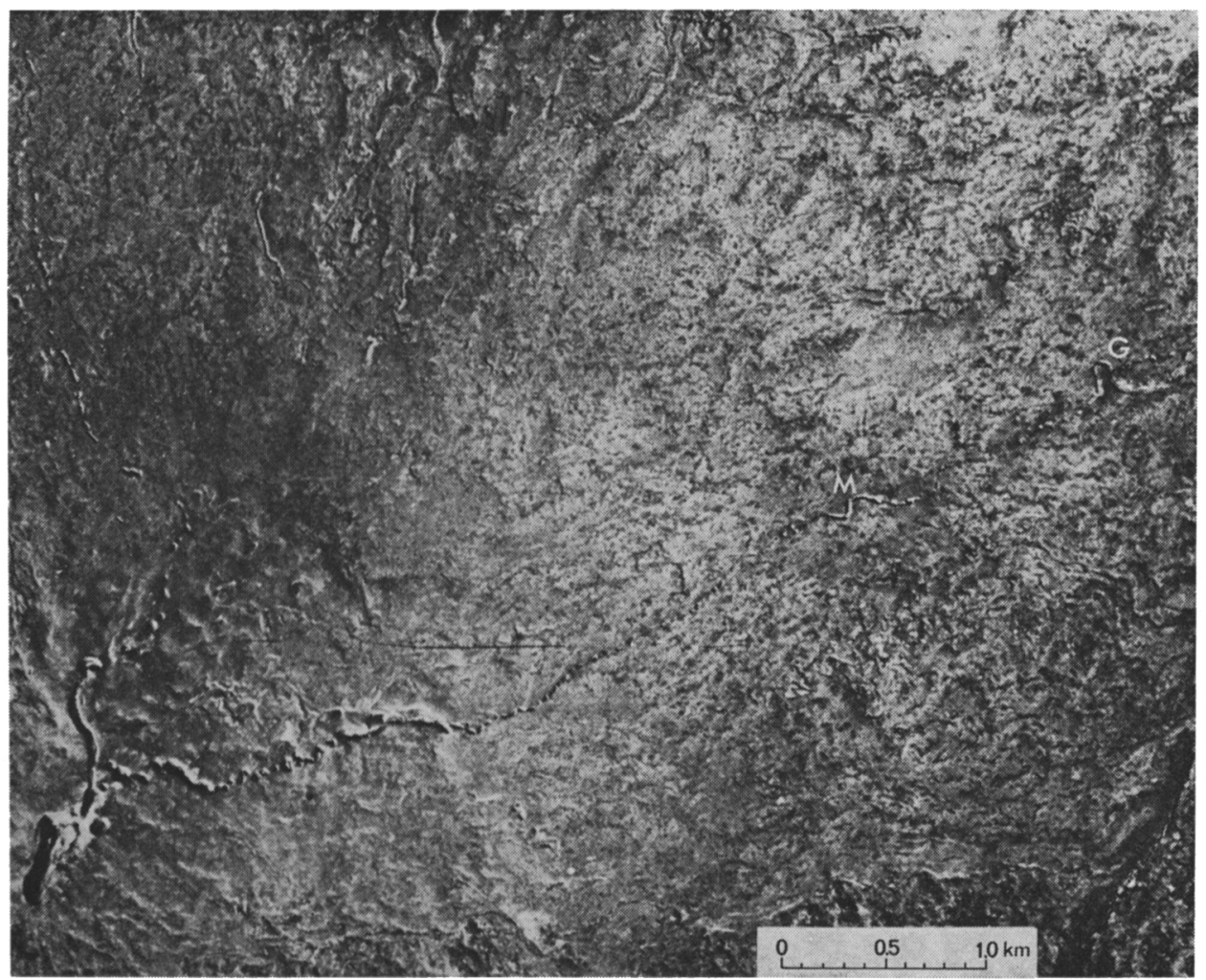

Fig. 7. Collapsed lava tubes on the Earth. 
sinuous rilles were dried up water rivers. In fact, with the easily explained exception that the lunar features are the larger, the morphological similarity between sinuous rilles (Figure 6) and collapsed lava tubes (Figure 7) on Earth is strong. For example, sinuous rilles are deflected by mountains and other topographic highs in a way that is not like the behaviour of water rivers but is characteristic of lava streams.

One or two sinuous rilles occupy the crests of broad rises (Greeley, 1970); or are associated with probable lava fronts - relations that testify to the volcanic origin of the rilles. Finally, measurements by Murray (1971) of the shape and meander parameters of sinuous rilles demonstrate that they follow the pattern of collapsed lava tubes and lava channels, rather than that of water rivers.

\section{Many Lunar Rilles are Collapse Features}

Some rilles (Figure 8) expose what may be layering in the rocks. Multiple concentric craters may also indicate lunar stratification. The most striking of these are the widely distributed, sharp-rimmed, double concentric craters. Oberbeck and Quaide (1968) reasoned that the larger of these craters was formed by the displacement of weakly

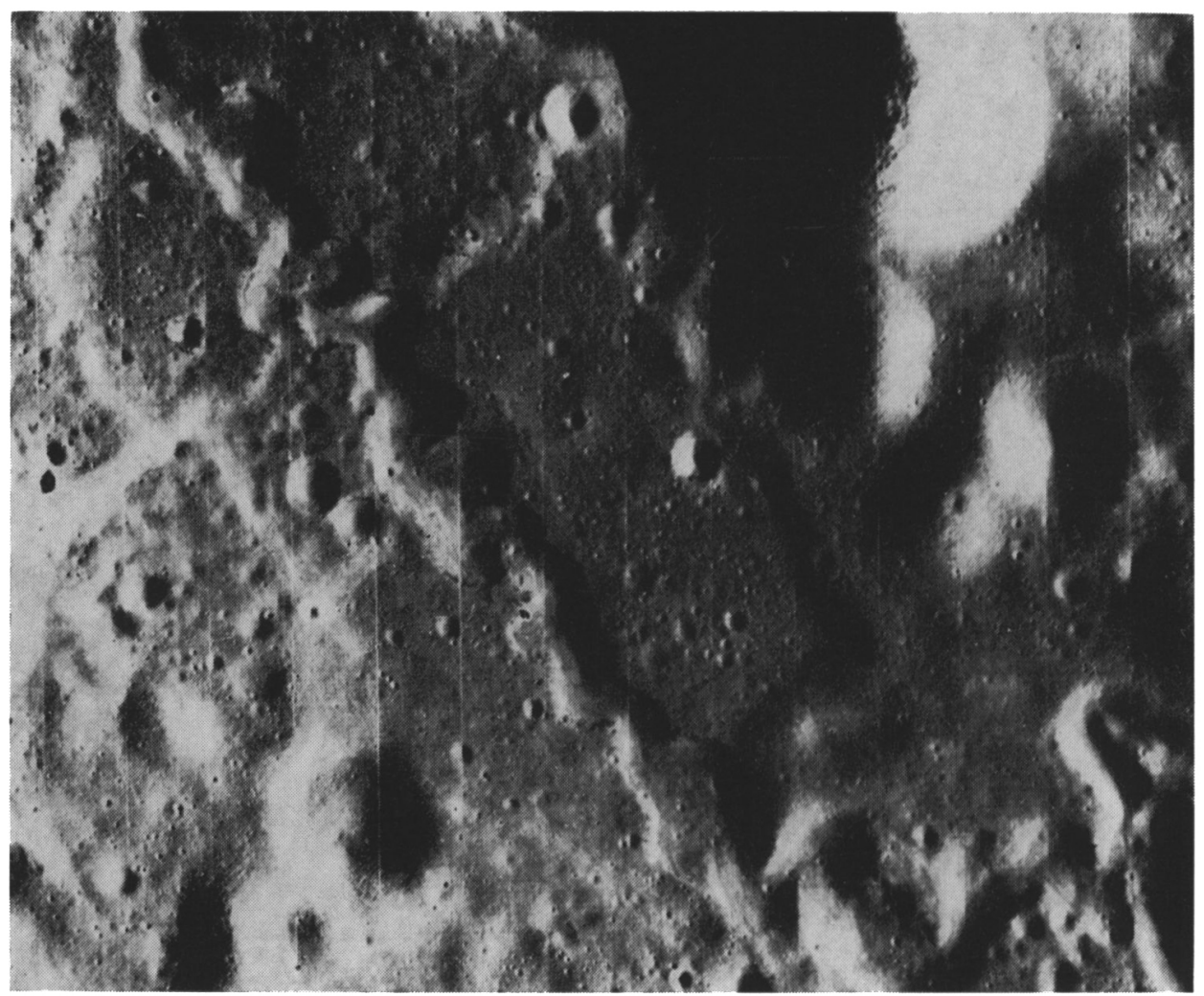

Fig. 8. A sinuous rille exposing probable layering of rocks in its banks. 
cohesive particles composing a lunar regolith or layer of rock fragments, and that the inner crater was excavated in more cohesive rock.

Evidence of a lunar regolith was contained in the Ranger 7 photographs of Mare Cognitum. The rock fragments of the highlands were excavated and analyzed using the Surveyor spacecraft, and further samples of fines - particles smaller than $1 \mathrm{~cm}$ in diameter - were returned from Mare Tranquillitatis by Armstrong and Aldrin and from Oceanus Procellarum by Conrad and Bean.

The composition of the lunar rocks is distinct from that of any other rocks. The characteristically high titanium in the dense rocks of the maria is probably the result of partial melting at depth followed by extrusion and crystal fractionation; and the dark tones of the maria, relative to the highlands, may be a result of the higher mare abundances of the iron group elements such as titanium. Sodium and potassium are low in abundance: they were probably lost from volcanic vents and flows.

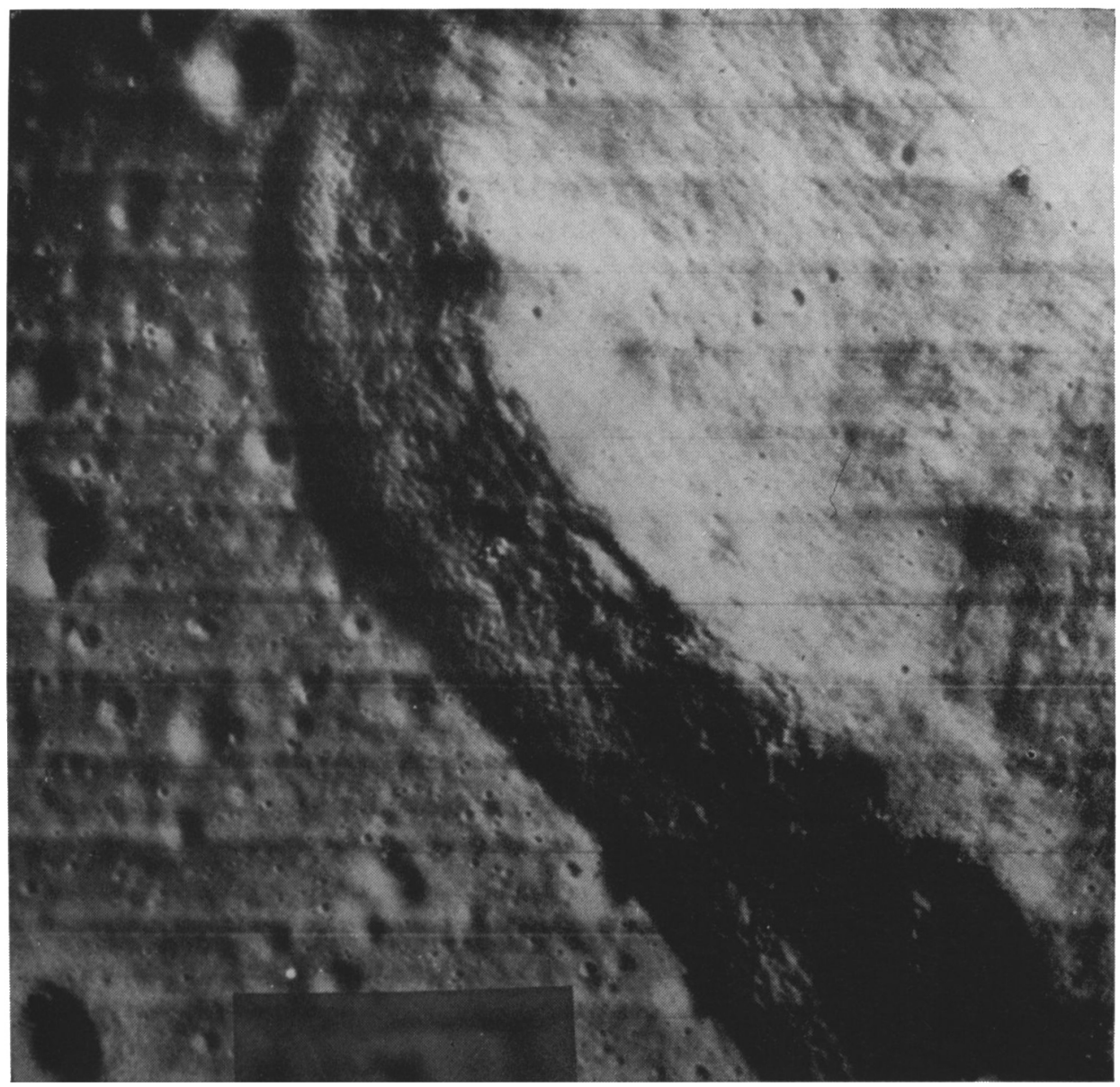

Fig. 9. Possible downslope creep of lunar material evidenced by crenulations on the flanks of a ridge. 
The composition of rocks at the Surveyor 7 highland site is close to that of the relatively low density anorthosite fragments found at the Apollo 11 site; and these fragments are thought to have come from the highlands. Possibly the highlands are generally less dense than the maria, and this raises the question of moonwide differentiation which, in turn, leads to the question of the Moon's magnetic field. Mixing of surface particles must follow their being injected into ballistic paths as a result of meteoroidal impact. Conrad and Bean found that Surveyor 3 had been covered after $2 \frac{1}{2}$ years on the Moon - with a layer of dust.

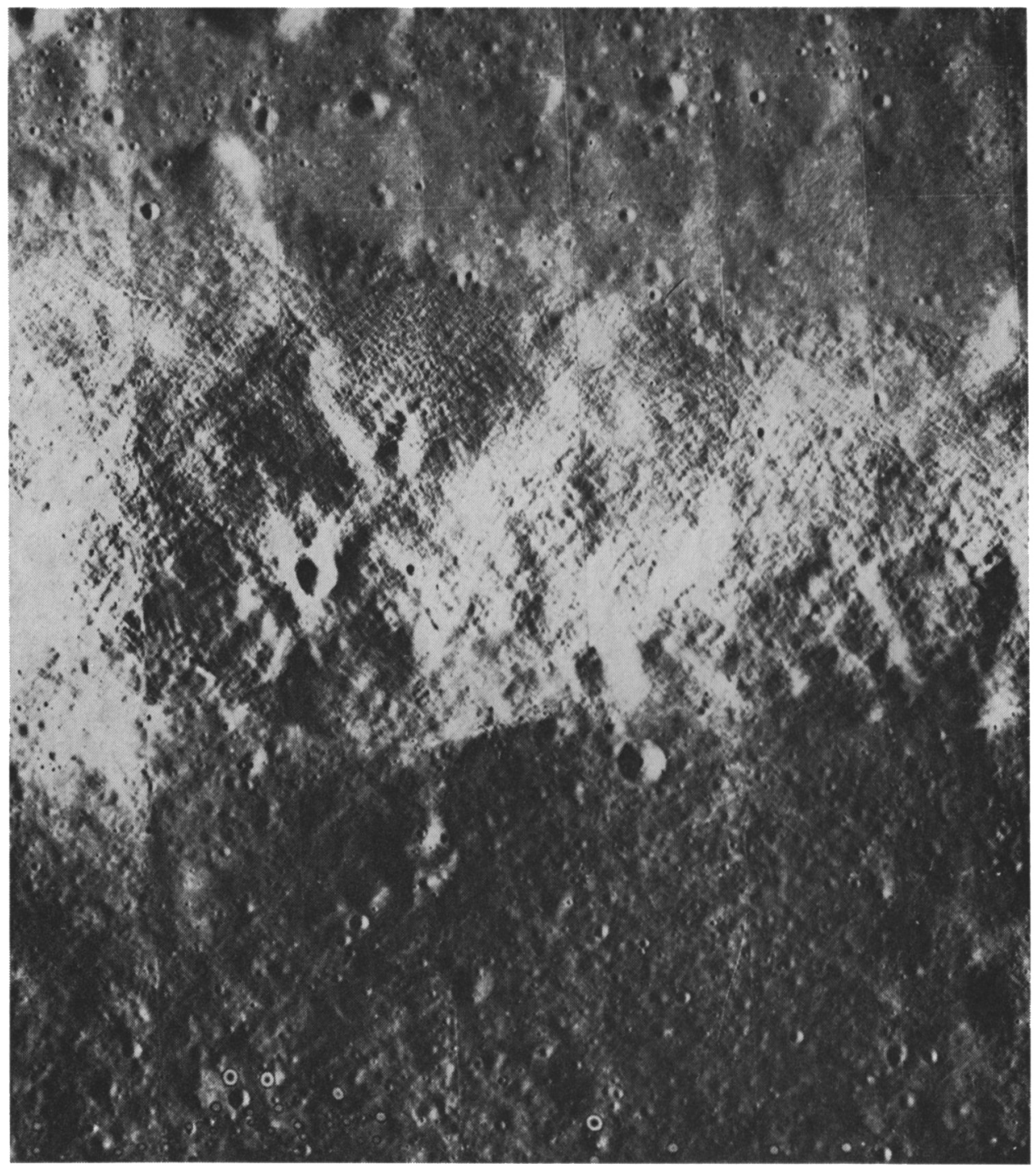

Fig. 10. Criss-crossing lunar lineaments in the wall of the lunar crater Prinz. 
Another, but more localized, lunar transportation process is that of mass wastage - the downslope migration of material evidenced by the crenulations (Figure 9) of the regolith on the flanks of eminences; and by the covering of earlier features at the feet of slopes. The regolith differs in thickness both locally and generally, from one region to another.

\section{Lunar Crust Lineaments}

The lunar surface has a criss-cross raked-over appearance. Spurr was one of the first to recognise the importance of what he termed the lunar grid system, in that it was controlled internally, by faulting, rather than by the mechanical process of impact.

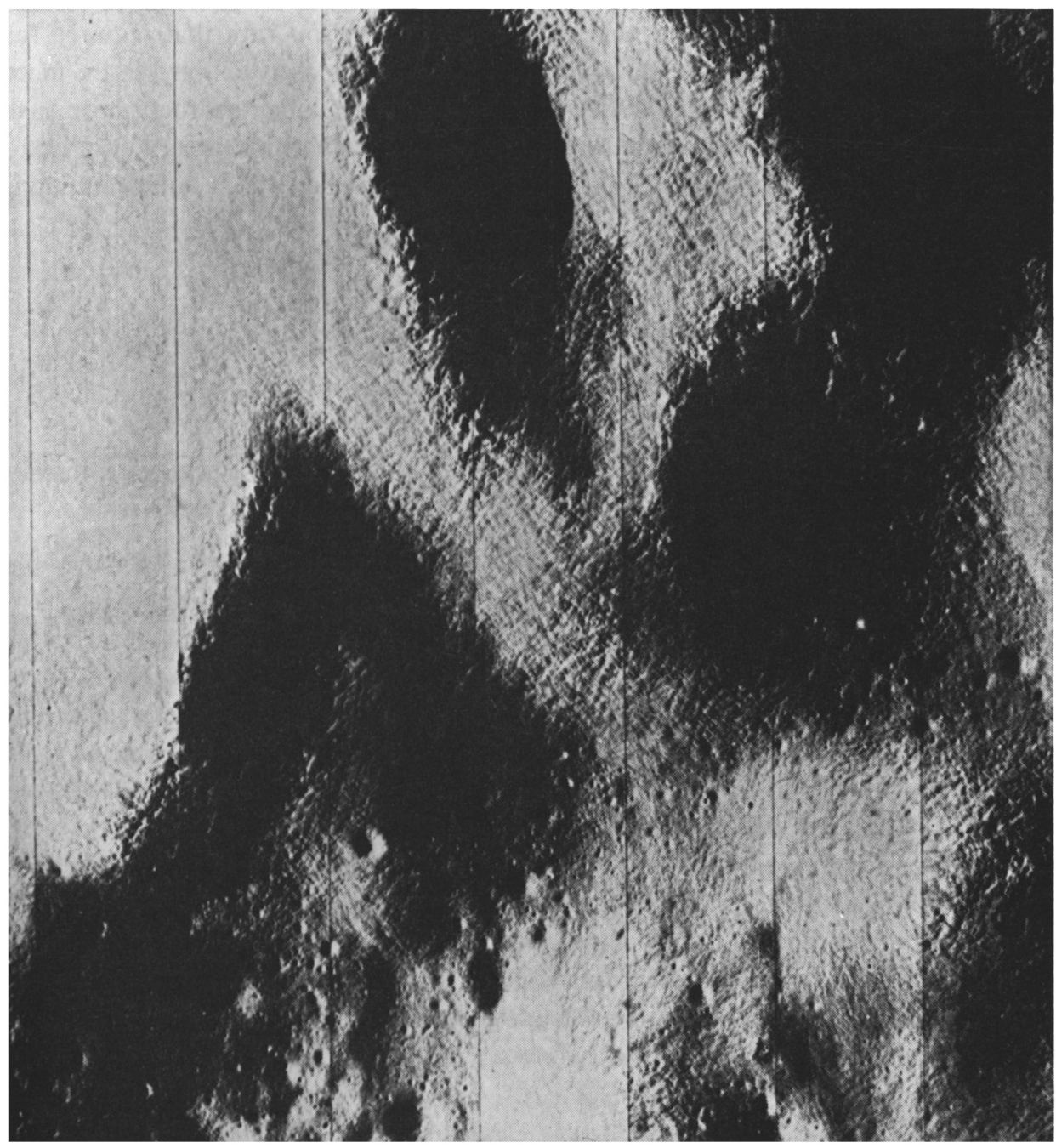

Fig. 11. High contrast photograph of portion of lunar Alps showing intersecting lineaments. 
Shoemaker et al. (1970) have now plotted the trends of lineaments only centimetres wide in Mare Tranquillitatis, photographed from the Moon's surface. The principal trends of these fine, linear troughs and ridges coincide with the directions of major lineaments, several of which are known to be tectonic in origin. Intermediate-sized lineaments crossing highland material are shown in Figures 10 and 11.

Exposure ages of the Apollo rocks indicate that the time scale of mixing of the top centimetre of regolith is several $\times 10^{6} \mathrm{yr}$. This mixing is primarily the result of the impacts of meteoroids, evidence for which is found in shocked material returned to Earth. Further evidence for natural impacts has been provided by Latham and others who interpreted the seismograms obtained through the Apollo 11 and 12 landings.

Clearly the incidence of primary and secondary impacts producing craters in the centrimetric size range is such that the internally derived grid pattern of the lunar surface is regenerated in a time that is short in comparison with that required for impacting objects to destroy it. Thus the regolith must be closely coupled to the more cohesive, underlying rock; and faults or fractures in the lunar bedrock must have moved or opened in the last several million years. In further interpretation of accumulated Apollo 12 seismograms, Ewing (1970) has now shown that lunar faulting is in progress to this day.

\section{References}

Ewing, M.: 1970, this volume, p. 155.

Fielder, G. and Fielder, J.: 1968, Boeing Sci. Res. Labs. Doc. D1-82-0749, 1.

Greeley, R.: 1970, preprint, Space Sci. Division, Ames Res, Center, Calif.

Muller, P. M. and Sjogren, W. L.: 1968, Science 161, 680.

Murase, T. and McBirney, A. R.: 1970, Science 167, 1491.

Murray, J. B.: 1970, in Geology and Physics of the Moon (ed. by G. Fielder), Chapter 3, Elsevier, Amsterdam.

Oberbeck, V. R. and Quaide, W. L.: 1968, J. Geophys. Res. 73, 5247.

Shoemaker, E. M., Hait, M. H., Swann, G. A., Schleicher, D. L., Dahlem, D. H., Schaber, G. G., and Sutton, R. L.: 1970, Science 167, 452.

Strom, R. G. and Fielder, G.: 1970, Commun. Lunar Planetary Lab. 8, 235; and in Geology and Physics of the Moon (ed. by G. Fielder), Chapter 5, Elsevier, Amsterdam.

Vedder, J. F.: 1966, Space Sci. Rev. 6, 365. 